\title{
Effect of different frequencies of fluoride dentifrice and mouthrinse administration: an in situ study
}

\section{Daniela Correia Cavalcante Souza(a) Lina Naomi Hashizume ${ }^{(a)}$ Morjana Eidelwein ${ }^{(b)}$ Marisa Maltz(a)}

\footnotetext{
(a) Department of Preventive and Social Dentistry, Faculty of Dentistry, Universidade Federal do Rio Grande do Sul, Porto Alegre, RS, Brazil.

(b) Faculty of Dentistry, Universidade Federal do Rio Grande do Sul, RS, Brazil
}

\begin{abstract}
The effect of a combination of topical fluoridation methods for inhibition of enamel demineralization in the face of a cariogenic challenge has not been clearly established. This in situ crossover study aimed to assess whether the addition of daily use of fluoride mouthrinse (FR) to that of fluoride dentifrice (FD) is equivalent to increasing the frequency of FD application in terms of the effect on enamel demineralization and fluoride content. Over 3 phases of 14 days each, 12 volunteers wore appliances containing enamel blocks exposed to a $20 \%$ sucrose solution 8 times/day. During each phase the blocks underwent one of the following treatments: $2 x /$ day FD, $2 x /$ day FD $+1 x /$ day FR, and 3x/day FD. The blocks were assessed for hardness and fluoride content. Three $\mathrm{x} / \mathrm{day}$ FD did not differ from $2 \mathrm{x} /$ day $+1 \mathrm{x} /$ day FR, however it enhanced demineralization protection when compared to $2 \mathrm{x} /$ day FD. All treatments produced an increase in enamel fluoride content compared to no treatment (sound blocks) $(\mathrm{p}<0.05)$, but the differences between them were not significant. The results of this study suggest that the daily use of fluoride mouthrinse combined with that of fluoride dentifrice has similar effects on enamel demineralization and fluoride content when compared to increasing the frequency of fluoride dentifrice use.
\end{abstract}

Descriptors: Fluorides; Dentifrices; Mouthwashes; Dental Caries.

\section{Introduction}

Fluoride dentifrices are effective vehicles for delivering fluoride to the population. Regular use of fluoride dentifrice is considered to be a beneficial preventive measure, independent of caries experience or oral health care. ${ }^{1}$ The greatest advantage of fluoride dentifrices when compared to alternative forms of topical application is the regular delivery of fluoride. ${ }^{2}$ The conventional toothbrushing frequency with fluoride dentifrice recommended to individuals is twice a day. However, for activecaries patients an increased frequency of topical fluoride administration is needed. ${ }^{3}$

Mouthrinses are also a simple method of fluoride self-application., ${ }^{4,5}$ Studies to assess the additional effect of fluoride mouthrinse combined with fluoride dentifrice are inconsistent. Some have shown benefits in terms of reduction of dental caries, ${ }^{6,7}$ while others have not. ${ }^{8,9}$ A metaanalysis of the effect of fluoride mouthrinses used in combination with fluoride dentifrice produced data in favor of the combined regimen, but
Received for publication on May 10, 2010 Accepted for publication on Aug 26, 2010 
differences were not statistically significant. Mouthrinses are usually recommended for active-caries patients in addition to normal use of fluoride dentifrice. $^{4}$

In vivo ${ }^{6-9}$ and in situ studies ${ }^{10-12}$ have shown that the frequency of topical fluoride applications is of importance to the effectiveness of caries preventive measures. Mouthrinses do not increase the fluoride exposure frequency, since they are usually applied immediately after the toothbrushing procedure..$^{13}$

Therefore, the effect of a combination of topical fluoride administration methods (dentifrice and mouthrinse) for inhibition of caries has not been clearly established. This study aimed to assess whether the addition of daily use of fluoride mouthrinse to that of fluoride dentifrice is equivalent to increasing the frequency of fluoride dentifrice application in terms of the effects on enamel demineralization and fluoride content.

\section{Materials and Methods Experimental design}

A randomized single-blind crossover in situ study was performed in 3 phases of 14 days each. Fifteen subjects [mean age $23.6( \pm 2.8)$ years], residents of an area with a fluoridated water supply $(0.7 \mathrm{ppmF})$ participated in the study. Inclusion criteria were: good general and dental health, normal salivary flow ( $\geq 0.7 \mathrm{~mL} / \mathrm{min}$ ), no antibiotic treatments in the 2 months preceding the study. The study was approved by the Ethics Committee of the Faculty of Dentistry at the Federal University of Rio Grande do Sul and all participants signed an informed consent form. The sample size calculation was based on previous findings using a similar experimental protocol to estimate the variability of data on enamel mineral loss. ${ }^{14}$ Each participant wore a removable mandibular appliance containing 2 bovine dental enamel blocks and for each phase a set of new enamel blocks was placed in the acrylic buccal flange of the appliance.

Volunteers were assigned into three groups using a computer-generated randomization list. The treatments were:

- T I - fluoride dentifrice twice a day (2x/day FD);

- T II - fluoride dentifrice twice a day followed by rinsing with fluoride solution once a day $(2 x /$ day $\mathrm{FD}+1 \mathrm{x} /$ day FR);

- T III - fluoride dentifrice three times a day $(3 \mathrm{x} /$ day FD).

During 7-day lead-in and wash-out periods the volunteers brushed their teeth with a non-fluoride dentifrice to eliminate possible residual effects. ${ }^{10}$ The products used were fluoride dentifrice (1100 ppm F as $\mathrm{NaF}$, silica-based, Dentics ${ }^{\circledR}$, Dentalprev Indústria e Comércio Ltda, São Paulo, São Paulo, Brazil) and non-fluoride dentifrice (free-fluoride, silica-based, Dentics ${ }^{\circledR}$ ), as well as fluoride mouthrinse (225 ppm $\mathrm{F}$ as NaF, Dentics $\left.{ }^{\circledR}\right)$. The volunteers were instructed to wear the appliances day and night and to remove them only during meals or oral care. For 1 minute during the volunteers' habitual oral hygiene with the experimental dentifrice, the appliances were removed and fluoride dentifrice slurry $(1: 3 \mathrm{w} / \mathrm{w})$ was dripped onto the specimens. ${ }^{15}$ After brushing, and before devices were put back into mouth, the volunteers rinsed their mouths with $10 \mathrm{~mL}$ of tap water for $10 \mathrm{~s}$. This procedure was performed for all treatments. When fluoride mouthrinse was also used ( $\mathrm{T}$ II), the volunteers were instructed to rinse their mouths with $10 \mathrm{~mL}$ of the solution for 1 minute immediately after nightly toothbrushing procedures after replacing the devices. To provide the cariogenic challenge, the volunteers were instructed to drip a $20 \%$ sucrose solution onto the blocks 8 times/day.

The volunteers did not receive any instructions with respect to their daily diet. At the end of each experimental phase, the enamel blocks were removed from the appliances and were assessed with respect to hardness and fluoride content.

\section{Preparation of enamel blocks and appliances}

Enamel blocks ( $3 \times 3 \times 2 \mathrm{~mm}$ ) were prepared from bovine incisors, and were sterilized through storage in a $2 \%$ formaldehyde solution, $\mathrm{pH} 7.0$, for at least 1 month. ${ }^{16}$ Enamel surfaces were ground and polished in order to allow surface hardness $(\mathrm{SH})$ to be determined. Ten untreated (sound) specimens were stored (humid atmosphere at $4^{\circ} \mathrm{C}$ ) to be used later as baseline control in the fluoride content analysis. 
Specimens were fixed leaving a $1 \mathrm{~mm}$ recess between the external surface of the enamel and the appliance. A plastic mesh was placed over the enamel blocks in order to retain dental biofilm.

\section{Surface hardness analysis}

SH was evaluated using a microhardness tester (Micrometer $^{\circledR}$ 2001, Buehler, Lake Bluff, Illinois, USA) with a Knoop diamond indenter under a $50 \mathrm{~g}$ load for $10 \mathrm{~s}$. Prior to the treatments, the average of five indentations was taken as baseline $\mathrm{SH}$. Enamel blocks with Knoop hardness number units $\left(\mathrm{Kg} / \mathrm{mm}^{2}\right)$ ratings ranging from 295.21 to 360.81 were selected. After the treatments, ten indentations spaced $100 \mu \mathrm{m}$ from baseline indentations (five on each side) were made and the mean value of all measurements was then recorded. The percentage of surface hardness change ( $\% \mathrm{SHC}$ ) was calculated $[\%$ SHC $=($ after treatment $\mathrm{SH}-$ baseline SH$) \times 100 /$ baseline $\mathrm{SH}$. After $\mathrm{SH}$ analysis, each enamel block was longitudinally sectioned and one half was submitted to cross-sectional hardness (CSH) testing and the other half to subsequent fluoride analysis. For CSH determination, the specimens were embedded in epoxy resin and the cut surfaces were exposed and polished. Three lanes of indentations were made: one in the center of the enamel block and the others $100 \mu \mathrm{m}$ below and above the first under a $25 \mathrm{~g}$ load for $10 \mathrm{~s}$. Indentations were made at $10,20,30,50,70,80$ and $100 \mu \mathrm{m}$ from the outer enamel surface. No mineral change was observed after $70 \mu \mathrm{m}$ depth. Mean values at each distance from the surface were converted to mineral content (vol. \% min. $)^{17}$ and the area of mineral loss $(\Delta \mathrm{Z})$ for each treatment was calculated by numerical integration using the trapezoidal rule.

\section{Fluoride content analysis}

With the exception of the polished surface, all the surfaces of the blocks were covered with an acid-resistant nail varnish. To determine the fluoride content three layers of enamel were sequentially removed from each block by immersion in $0.25 \mathrm{~mL}$ of a solution of 0.5 mol. $\mathrm{L}^{-1} \mathrm{HCl}$ for 15,30 and 60 s under agitation..$^{18}$ An equal volume of TISAB II, $\mathrm{pH} 5.0$, modified with $20 \mathrm{~g} \mathrm{NaOH} / \mathrm{L}$, was added to each solution. Fluoride measurement was performed using a fluoride-sensitive electrode (Orion 9609, Orion Research Inc., Beverly, Massachusetts, USA) connected to an ion analyzer SA-720 (Procyon Instrumentos Científicos, São Paulo, São Paulo, Brazil). The fluoride content values found in each layer were summed and expressed as $\mu \mathrm{g} F / \mathrm{cm}^{2}$ enamel surface.

\section{Statistical analysis}

The volunteer was defined as experimental unit. Analysis of variances (ANOVA) followed by Tukey's multiple comparison test was used to analyze $\%$ SHC, $\Delta \mathrm{Z}$ and fluoride content. Student's $t$ test was used to compare fluoride content values between the test and the untreated blocks. The software used was SPSS 8.0 for Windows (SPSS Inc., Chicago, Illinois, USA). The significance level used was $5 \%$.

\section{Results}

Two subjects were excluded due to antibiotic treatments and one subject failed to complete one experimental phase. These subjects were not included in the data analyses $(n=12)$.

\section{Surface hardness analysis}

Table 1 lists the data for surface hardness and $\Delta \mathrm{Z}$ after the experimental periods. The treatments were not capable of completely eliminating enamel demineralization. The initial SH was similar for all groups. Group T III exhibited a lower \%SHC compared to group T I $(\mathrm{p}<0.05)$. The \% SHC of groups $\mathrm{T}$ II and T III were similar. All treatments exhibited a similar area of enamel mineral loss.

\section{Fluoride content analysis}

Table 2 lists the results of fluoride content analysis for untreated and treated specimens. The enamel blocks exposed to treatments exhibited a significant increase in fluoride content when compared to the untreated blocks $(\mathrm{p}<0.001)$, but no significant differences could be detected between different treatments.

\section{Discussion}

This study tested different topical fluoride regi- 
Table 1 - Surface hardness $\left(\mathrm{kg} / \mathrm{mm}^{2}\right)$ of the enamel blocks before (baseline) and after the intraoral periods, \% SHC and mineral loss $(\triangle Z)$, (mean $\pm \mathrm{SD})$.

\begin{tabular}{|c|c|c|c|c|c|}
\hline \multirow{2}{*}{ Treatments } & \multicolumn{4}{|c|}{ Surface hardness } & \multirow{2}{*}{$\Delta Z$ (vol. \% min. $x \mu \mathrm{m}$ ) } \\
\hline & $\mathrm{n}$ & Baseline & After treatment & $\% \mathrm{SHC}$ & \\
\hline TI (2x/day FD) & 12 & $327.7 \pm 11.7$ & $245.8 \pm 69.0$ & $-25.3 \pm 20.8^{a}$ & $395.5 \pm 184.4^{a}$ \\
\hline TII (2x/day FD + 1x/day FR) & 12 & $330.7 \pm 15.0$ & $251.2 \pm 53.2$ & $-24.0 \pm 16.2^{a b}$ & $354.6 \pm 172.0^{a}$ \\
\hline TIII (3x/day FD) & 12 & $333.6 \pm 14.6$ & $296.4 \pm 30.4$ & $-11.0 \pm 8.9^{b}$ & $331.2 \pm 156.8^{a}$ \\
\hline
\end{tabular}

$\mathrm{FD}=$ fluoride dentifrice; $F R=$ fluoride rinse $\% \mathrm{SHC}=$ surface hardness change; $\Delta \mathrm{Z}=$ area of enamel mineral loss. Means followed by different letters are statistically significant ( $p<0.05$, ANOVA, followed by Tukey's multiple comparison test).

\begin{tabular}{|c|c|c|c|}
\hline \multirow{4}{*}{$\begin{array}{r}\text { Table } 2 \text { - Fluoride } \\
\text { content (mean } \pm \text { SD) } \\
\text { of untreated enamel } \\
\text { specimens and specimens } \\
\text { submitted to different } \\
\text { treatments. }\end{array}$} & Treatments & $\mathrm{n}$ & Fluoride content $\left(\mu \mathrm{g} \mathrm{F} / \mathrm{cm}^{2}\right)$ \\
\hline & No treatment & 10 & $1.5 \pm 0.5^{a}$ \\
\hline & TI (2x/day FD) & 12 & $8.2 \pm 6.2^{b}$ \\
\hline & T II (2x/day FD + 1x/day FR) & 12 & $11.2 \pm 5.3^{b}$ \\
\hline & T III (3x/day FD) & 12 & $9.8 \pm 2.8^{b}$ \\
\hline
\end{tabular}

mens in a model of high caries risk. ${ }^{19}$ There was greater formation of cariogenic biofilm when exposure to sucrose was $8 \mathrm{x} /$ day in comparison with $4 \mathrm{x} /$ day. ${ }^{15}$ In this study, the enamel blocks were exposed $8 \mathrm{x} /$ day to a $20 \%$ sucrose solution. All of the fluoride regimens tested exhibited decreased surface hardness. Ionic fluoride delivered by fluoridation methods may diffuse into the biofilm, which becomes saturated by them. ${ }^{20}$ The presence of fluoride ions in the oral environment may interfere in the carious process by inhibiting demineralization. In situ studies have shown that the presence of fluoride can reduce enamel demineralization if sucrose consumption is not higher than 6 times/day, but it is not able to completely inhibit demineralization under such conditions. ${ }^{21}$ In this way, the presence of fluoride ions in the oral environment may interfere in the carious process by inhibiting demineralization.

When a highly cariogenic challenge exists, residual fluoride in saliva after daily use of fluoride dentifrice is able to reduce enamel mineral loss but cannot eliminate it. The mineral loss observed after 3-times daily use of fluoride dentifrice in this in situ study was in line with results published by others. ${ }^{14}$

When enamel is exposed to acids produced in the dental biofilm, the mineral is removed or dissolved from the solid mineral. This results in enlargement of intercrystalline spaces and can be observed as an increase in the tissue porosity of the outer enamel surface. Demineralized enamel surface is therefore more porous. Quantification of changes in the tissue porosity can be used as an early indicator of mineral loss. Assuming an intermittent highly cariogenic challenge, there will be a formation of subsurface lesion. ${ }^{22}$ For this reason, changes in enamel porosity are a very sensitive indicator of even very small changes in mineral content. In this study, the treatment with the highest frequency of topical fluoride administration (3x/day FD) exhibited lower \%SHC than did the $2 x /$ day FD treatment. The addition of a fluoride mouthrinse to the twice daily toothbrushing procedure did not decrease surface porosity. This result suggests a greater therapeutic effect (demineralization control) when a higher frequency of topical fluoride administration ( $3 \mathrm{x} /$ day $\mathrm{FD}$ ) is compared to the combined use of topical fluoride treatments with no increase in frequency of fluoride exposure $(2 \mathrm{x} /$ day FD + 1x/day FR). Although the treatments differed in surface hardness they were similar in terms of area of mineral loss. These treatments did not show subsurface lesions, as has been reported by others. ${ }^{14}$ 
The present study showed that in the presence of a highly cariogenic challenge, fluoride therapy increased the fluoride content of the enamel blocks. ${ }^{18}$ The increased frequency of fluoride treatment used in this study was not sufficient to influence the fluoride content of the sound enamel blocks subjected to cariogenic challenge. Several studies testing fluoride therapy on demineralized enamel blocks have shown that fluoride content is dependent on the frequency of topical application. ${ }^{12,23}$ One possible explanation for the difference observed between studies using previously demineralized enamel blocks versus sound enamel blocks submitted to cariogenic challenge may be that fluoride uptake in the latter experiments reached a plateau. According to Raven et al. ${ }^{24}$ the increased porosity and surface area of demineralized enamel increases its reactivity by allowing the fluoride to diffuse more readily into the enamel. Sound enamel has a smaller surface area for absorption of fluoride compared to demineralized enamel. The lower surface area of sound enamel subjected to cariogenic challenge in the presence of fluoride may account for the failure to observe a dose response due to saturation of the enamel surface. Considering the outcomes of all variables analyzed, 3x/day FD did not differ from $2 \mathrm{x} /$ day $+1 \mathrm{x} /$

\section{References}

1. Delbem ACB, Carvalho LPR, Morihisa RKU, Cury JA. In vitro comparison of the cariostatic effect between topical application of fluoride gels and fluoride toothpaste. J Appl Oral Sci. 2004 Jun;12(2):121-6.

2. Mellberg JR, Chomicki WG. Effect of soluble calcium on fluoride uptake by artificial caries lesions in vivo. Caries Res. 1985 Mar-Apr;19(2):122-5.

3. Marinho VC, Higgins JP, Sheiham A, Logan S. Fluoride toothpastes for preventing dental caries in children and adolescents. Cochrane Database Syst Rev 2003;(1):CD002278.

4. Marinho VCC, Higgins JPT, Sheiham A, Logan S. Combinations of topical fluoride (toothpastes, mouthrinses, gels, varnishes) versus single topical fluoride for preventing dental caries in children and adolescents. Cochrane Database Syst Rev 2003;(1):CD002781.

5. Petersson LG. Fluoride mouthrinses and fluoride varnishes. Caries Res. 1993 Apr;27 Suppl 1:35-42.

6. Karjalainen S, Eriksson AL, Ruokola M, Toivonen A. Caries development after substitution of supervised fluoride rinses day FR, however it enhanced demineralization control when compared to $2 \mathrm{x} /$ day FD. It is important to point out that rinsing solutions require individuals to use another product in addition to the dentifrice normally used in routine oral hygiene procedures. For active-caries individuals, it may be more costeffective to increase the frequency of fluoride dentifrice instead of adding another fluoride treatment (mouthrinsing).

\section{Conclusions}

The results of this study suggest that the daily use of fluoride mouthrinse combined with fluoride dentifrice has similar effects on enamel demineralization and fluoride content when compared to increasing the frequency of fluoride dentifrice use.

\section{Acknowledgements}

The authors would like to thank the volunteers from the Faculty of Dentistry (UFRGS) for their valuable participation in this study; the Laboratory of Ceramic Materials (UFRGS) for providing the microhardness tester, and Dentalprev Indústria e Comércio Ltda for preparing and donating the dentifrices and mouthrinses.

and toothbrushings by unsupervised use of fluoride toothpaste. Community Dent Oral Epidemiol. 1994 Dec; 22(6):4214.

7. Ringelberg ML, Webster DB, Dixon DO, LeZotte DC. The caries-preventive effect of amine fluorides and inorganic fluorides in a mouthrinse or dentifrice after 30 months of use. $\mathrm{J}$ Am Dent Assoc. 1979 Feb;98(2):202-8.

8. Ashley FP, Mainwaring PJ, Emslie RD, Naylor MN. Clinical testing of a mouthrinse and a dentifrice containing fluoride. A two-year supervised study in school children. Br Dent J. 1977 Nov;143(10):333-8.

9. Axelsson P, Paulander J, Nordkvist K, Karlsson R. Effect of fluoride containing dentifrice, mouthrinsing, and varnish on approximal dental caries in a 3-year clinical trial. Community Dent Oral Epidemiol. 1987 Aug;15(4):177-80.

10. Cury JA, Hashizume LN, Del Bel Cury AA, Tabchoury CPM. Effect of dentifrice containing fluoride and/or baking soda on enamel demineralization/remineralization: an in situ study. Caries Res. 2001 Mar-Apr;35(2):106-10. 
11. Meyerowitz C, Featherstone JDB, Billings RJ, Eisenber AD, $\mathrm{Fu}$ J, Shariati M, et al. Use of an intra-oral model to evaluated $0.05 \%$ sodium fluoride mouthrinse in radiation-induced hiposalivation. J Dent Res. 1991 May;70(5):894-8.

12. van Strijp AA, Buijs MJ, ten Cate JM. In situ fluoride retention in enamel and dentine after the use of an amine fluoride dentifrice and amine fluoride/sodium fluoride mouthrinse. Caries Res. 1999 Jan-Feb;33(1):61-5.

13. Marinho VC, Higgins JP, Logan S, Sheiham A. Fluoride mouthrinses for preventing dental caries in children and adolescents. Cochrane Database Syst Rev 2003;(3):CD002284.

14. Paes Leme AF, Dalcico R, Tabchoury CPM, Del Bel Cury AA, Rosalen PL, Cury JA. In situ effect of frequent sucrose exposure on enamel demineralization and on plaque composition after APF application and F dentifrice use. J Dent Res. 2004 Jan;83(1):71-5.

15. Cury JA, Francisco SB, Simões GS, Del Bel Cury AA, Tabchoury CPM. Effect of a calcium carbonate-based dentifrice on enamel demineralization in situ. Caries Res. 2003 MayJun;37(3):194-9.

16. White DJ, Featherstone JDB. A longitudinal microhardness analysis of fluoride dentifrice effects on lesion progression in vitro. Caries Res. 1987 Nov-Dec;21(6):502-12.

17. Featherstone JDB, ten Cate JM, Shariati M, Arends J. Comparison of artificial caries-like lesions by quantitative microradiography and microhardness profiles. Caries Res. 1983 Sep-Oct;17(5):385-91.
18. Paes Leme AF, Tenuta LMA, Del Bel Cury AA, Tabchoury COM, Cury JA. Efeito da associação da aplicação tópica de fluoreto profissional e de dentifrício no esmalte dental. Rev Gaucha de Odontol. 2007 Jan-Mar;55(1):35-40.

19. Nyvad B, ten Cate JM, Fejerskov O. Arrest of root surface caries in situ. J Dent Res 1997 Dec;76(12):1845-53.

20. Cury JA, do Amaral RC, Tenuta LMA, Del Bel Cury AA, Tabchoury CPM. Low-fluoride toothpaste and deciduous enamel demineralization under biofilm accumulation and sucrose exposure. Eur J Oral Sci. 2010 Aug;118(4): 370-5.

21. Duggal MS, Toumba KJ, Amaechi BT, Kowash MB, Hogham SM. Enamel demineralization in situ with various frequencies of carbohydrate consumption with and without fluoride toothpaste. J Dent Res. 2001;80:1721-4.

22. Holmen L, Thylstrup A, Artun J. Surface changes during the arrest of active enamel carious lesions in vivo. A scanning electron microscope study. Acta Odontol Scand. 1987 Dec;45(6):383-90.

23. Jardim JJ, Pagot MA, Maltz M. Artificial enamel dental caries treated with different topical fluoride regimes: an in situ study. J Dent. 2008 Jun;36(6):396-401.

24. Raven SJ, Schäfer F, Duckworth RM, Gilbert RJ, Parr TA. Comparison between evaluation methods for the anticaries efficacy of monofluorophosphate-containing dentifrices. Caries Res. 1991 Mar-Apr;25(2):130-137. 